\title{
BREVE DRAMATURGIA DA MEMÓRIA: oficina de teatro com idosos
}

Beatriz Pinto Venancio ${ }^{1}$

\section{Resumo}

Este artigo procura refletir o processo de um grupo de teatro formado por idosos não-atores. A linguagem teatral é utilizada como um recurso na compreensão das subjetividades desses idosos, a partir da encenação de suas lembranças. Desse modo, cria-se um novo canal de comunicação de memórias.

Palavras-chave: Envelhecimento. Memória. Teatro.

\section{Introdução}

Não é necessário ser um estudioso na área de gerontologia, nem mesmo consultar a literatura especializada, para perceber que investigações sobre a velhice têm crescido nos últimos anos. Somos diariamente informados pelos meios de comunicação sobre o envelhecimento da população mundial e de suas importantes repercussões nos campos social, político e econômico.

As Universidades e os responsáveis por projetos voltados para essa faixa etária têm um papel fundamental no enfrentamento dessa questão, contribuindo com propostas inovadoras e considerável produção de conhecimento na área. O Programa de Extensão UFF Espaço Avançado² da Universidade Federal Fluminense, voltado para a população idosa, inserese nesse contexto. Além das lutas, reflexões e debates sobre a participação do idoso nesta sociedade tão desigual, a equipe do "Espaço", formada por docentes de diversos departamentos, discentes e profissionais de várias áreas, busca oportunizar experiências estéticas em diferentes linguagens, anteriormente negadas a essas pessoas. Mais do que ocupar o tempo livre, o que propomos aos idosos é, em um ambiente lúdico, experimentar o prazer do debate, do conhecimento, das artes e do trabalho corporal. O eixo norteador do Programa é a cidadania do idoso, e o trabalho é organizado em oficinas permanentes nas diferentes áreas de atuação. A Oficina de

\footnotetext{
1 Mestre em Serviço Social (PUC-RJ), Doutora em Teatro (UNIRIO), Professora do Departamento de Serviço Social de Niterói (UFF) e Coordenadora da Oficina de Teatro e Memória do Programa de Extensão UFF Espaço Avançado. E-mail: beavenancio@uol.com.br

2 Atualmente coordenado pela assistente social Maria Carmen Alvarenga
} 
Teatro e Memória, coordenada por mim, tem por objetivo propiciar a um grupo de idosos o repensar sobre suas vidas por meio da encenação de suas lembranças.

\section{As Oficinas}

Há nove anos coordeno este grupo permanente de teatro formado por pessoas com idades entre 55 e 85 anos. São cerca de 25 mulheres e quatro homens, moradores da cidade de Niterói e seu entorno, com graus de escolaridade diversos e, em sua maioria, aposentados ou pensionistas. Grande parte desta trupe não tinha experiência teatral alguma e pisou em um teatro pela primeira vez na estréia de um de nossos espetáculos, saltando a platéia e dirigindo-se ao palco.

Com base nas memórias desse grupo, aleatórias ou provocadas, montamos seis espetáculos. A partir de então, demos continuidade à pesquisa $\mathrm{e}$ estamos criando um arquivo de histórias de vida. O acervo é formado pelas longas entrevistas realizadas com os participantes do grupo. Este artigo trata da utilização das histórias de vida transformadas em fonte para a elaboração do texto dramatúrgico e montagem de espetáculos. Os procedimentos incluem a extração de diversos acontecimentos contidos nessas histórias e transformados em material para improvisações. Os jogos e exercícios garantem a teatralidade para esses eventos, ora fragmentados, ora unidos por um nexo fornecido pelo próprio grupo. A investigação reúne, portanto, a construção do arquivo de histórias de vida de pessoas comuns, a comunicação de memórias pela via teatral, o exercício da escrita dramatúrgica e a inclusão social de indivíduos idosos.

Durante estes anos de pesquisa, experimentamos diversas maneiras de teatralizar as memórias, criando uma série de elementos provocadores de lembranças ${ }^{3}$. Em um primeiro momento, que denominei tempestade de lembranças, cada participante poderia contar histórias do passado, sem tema ou cronologia. As lembranças reorganizadas nas improvisações permitiram a criação de um roteiro com duas personagens a quem os participantes do grupo ofereciam porções de suas vidas. O eixo central foi constituído pelas vivências dos casamentos, contadas evidentemente do ponto de vista das mulheres que naquele momento formavam o grupo. Cenas aparentemente

3 Os três primeiros espetáculos foram analisados detalhadamente em minha tese de Doutorado "Teatro de Lembranças: registro cênico-dramatúrgico de memórias de velhos" (VENANCIO, 2004), orientada pela Prof a . Dr ${ }^{\mathrm{a}}$. Maria Helena Werneck, defendida em 2004 no Programa de Pós-Graduação em Teatro da UNIRIO, com apoio da Capes - PDEE. A tese foi publicada com o titulo Pequenos Espetáculos da Memória, pela Editora Hucitec em 2008. 
soltas no tempo foram construindo um mural de seus casamentos imperfeitos e levaram à criação do espetáculo Que Deus o Tenha!

No segundo momento, usamos exercícios de teatro-imagem de Augusto Boal $^{4}$ (1996), criando imagens de família e de sonho profissional. Durante dois meses, trabalhamos imagens de família do passado e contemporâneas, além das imagens de profissões desejadas e nunca exercidas pelas pessoas do grupo. O roteiro do texto, surgido a partir dessa experiência com imagens, ganhou uma personagem principal, uma jovem dos anos 40 , que sonhava em ser atriz, composta de múltiplos traços de cada uma delas, resultando no espetáculo $O$ Sonho de Glorinha.

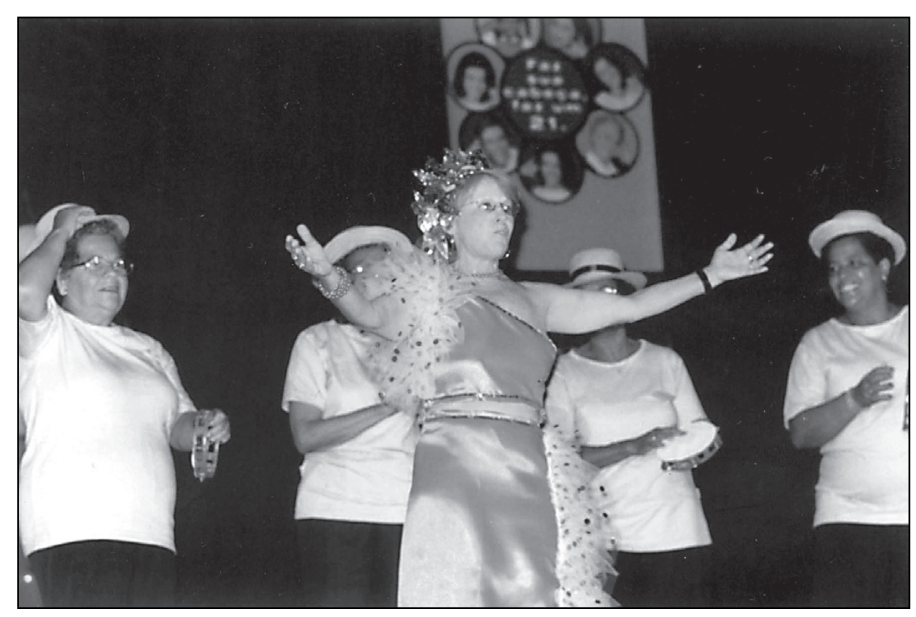

Fotografia 1: O Sonho de Glorinha.

No terceiro momento, denominado porções de memória em pequenos papéis, trabalhamos com textos escritos pelo grupo, costurando uma temporalidade que abrigasse uma vida inteira. O procedimento adotado visou a preservar o relato e a narrativa na sua expressão original. Um vaivém entre o relato e o teatro, entre o contador e o ator, entre o "ele" e o "eu". Nesta experiência, a memória chegou concentrada e já escrita, sendo rearranjada e reorganizada apenas para ganhar teatralidade. A história brotou da boca de um narrador de vários rostos, aprendiz de contador, que, contando a sua vida de uma forma épico-lírica, fez surgir o espetáculo Monólogo de Muitas Vidas.

\footnotetext{
4 Augusto Boal, diretor, dramaturgo e criador do Teatro do Oprimido. A técnica do teatro-imagem, criada por ele, é uma maneira de compreender as representações de pessoas, grupos e da coletividade sobre determinados temas, sentimentos e vivências.
} 


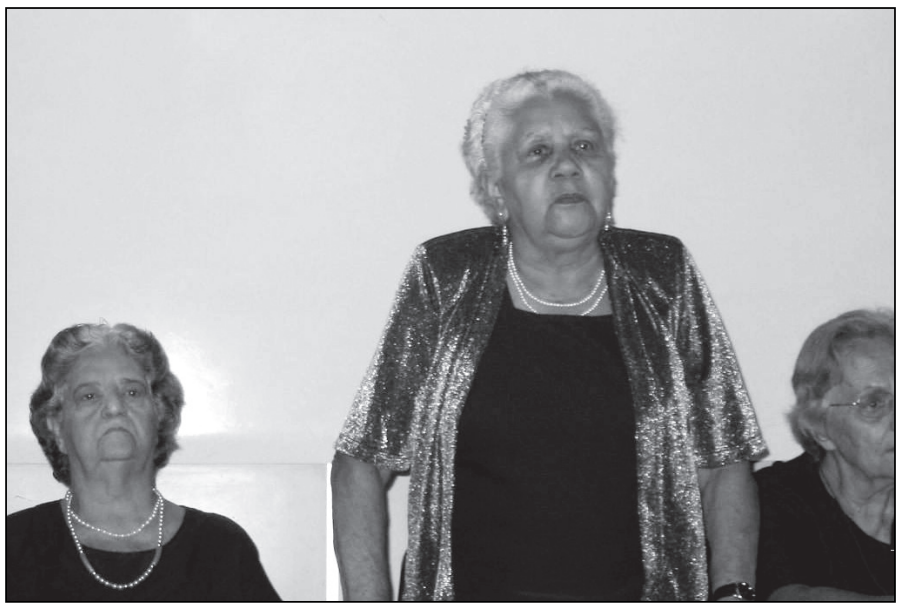

Fotografia 2: Monólogo de Muitas Vidas.

Neste espetáculo, pela primeira vez, o título não é retirado da matéria das lembranças e remete a um gênero dramatúrgico convencional. Monólogo, nesta pesquisa, foi utilizado indicando uma forma de organização das lembranças, com um tempo acelerado, abarcando uma vida inteira em um só ato. O tom lírico, quase confessional, predomina no modo semi-autobiográfico de trazer as memórias para a cena, oscilando entre o dramático e o narrativo. A introdução do narrador permitiu importantes variações. Dirigindo-se ao público, tornou clara a sua presença, reconhecendo e destruindo a quarta parede 5 " [... ] que improvisações fechadas na sua própria pesquisa poderiam ser tentadas a manter." (RYNGAERT, 1981, p. 203); permitiu a construção da história, organizando as cenas e criando momentos de reflexão. A ficção que daí surgiu revelou uma escrita perturbada, com esconderijos que guardaram o que não poderia ser revelado, o que era preciso ser preservado ou mesmo esquecido. As vozes dos narradores carregaram a palavra deles mesmos e dos outros, conjugando-se na subjetividade do próprio narrador, de sua existência real, impregnada das existências alheias, presentes e ausentes, dos contextos sociais e comunitários em que foram vivenciadas e circunscritas no território da investigação que as fez aflorar.

Partimos, então, para novas experimentações, propondo temas para o surgimento das memórias, originando mais dois espetáculos. Nós no Tempo reuniu lembranças da infância, da vida escolar e de momentos atuais, de-

5 Termo utilizado no Teatro, refere-se a uma parede imaginária entre o público e o palco. O ato de derrubar ou destruir a quarta parede é uma explicitação da representação teatral. $\mathrm{O}$ ator dirige-se à platéia, relaciona-se com as pessoas que o assistem. Esta atitude faz com que o público lembre-se que está diante de uma ficção. 
nunciando, com humor e ironia, os preconceitos e discriminações vividos pela pessoa idosa.

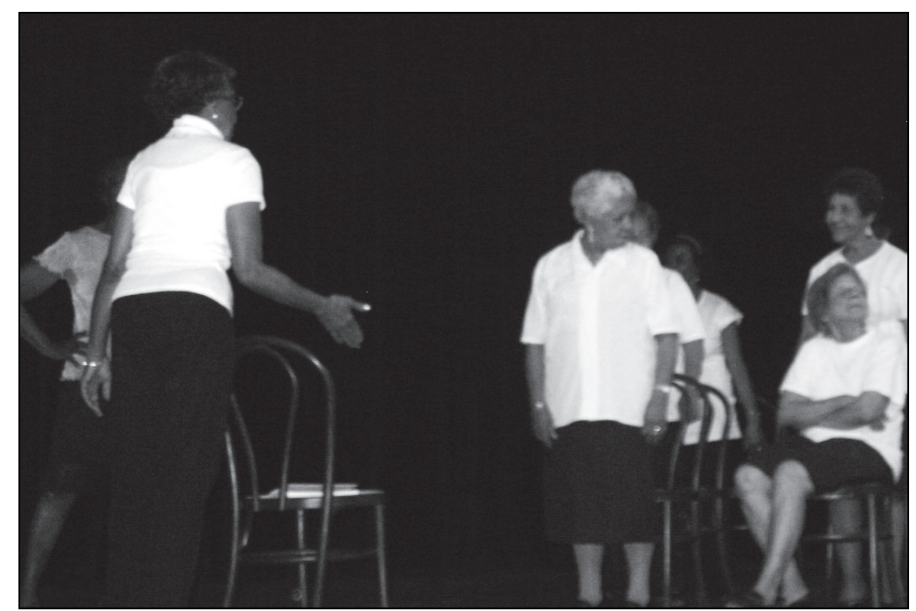

Fotografia 3: Nós no Tempo.

E Um Boteco e suas Histórias, sobre os acontecimentos culturais e políticos das décadas de 1960 e 1970 influenciando o dia-a-dia dos participantes do grupo. O que estavam fazendo no momento do golpe de 64, dos festivais da Record, da conquista do tetra na copa do mundo? Em um cenário de bar, as histórias se cruzam e se misturam ao som de músicas da época cantadas pelos próprios atores.

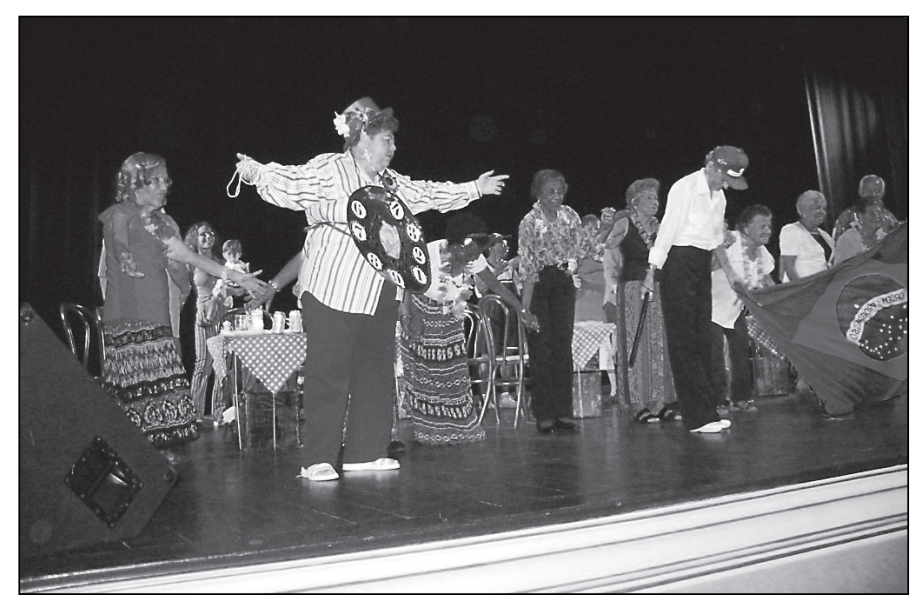

Fotografia 4: Um Boteco e suas Histórias 
Nos dois últimos anos de trabalho, temos trabalhado diretamente com o arquivo de histórias de vida dos participantes. Após as longas entrevistas, peço que o próprio entrevistado selecione acontecimentos que gostaria de levar para as oficinas, como material para improvisações e construção do espetáculo. Andanças de um Viajante foi baseado na vida de um senhor que, por motivos de trabalho, viajou pelo interior do país vivendo situações inusitadas. Neste processo de trabalho, a história de vida é compartilhada com o grupo para que todos conheçam o contexto e se aproximem daquela existência narrada. $\mathrm{O}$ entrevistado revela para o grupo os acontecimentos destacados por ele e, então, iniciamos os exercícios de oficina. Nesta etapa, o estudo da literatura oral foi fundamental. Nos antigos contadores, a expressão teatral era essencialmente oral, uma socialização da experiência individual. Qualquer que fosse a extensão de seus relatos orais, o contador era antes de tudo o homem dos detalhes significativos, um colecionador de gestos socializados (VANOYE; MOUCHON; SARRAZAC, 1991).

As improvisações, trabalho intenso e longo, foram, aos poucos, garantindo teatralidade para a história a ser contada. Unindo narração, representação, música e trabalho corporal, surgiu, enfim, o espetáculo Andanças de um Viajante, que ao mesmo tempo conta a história de uma pessoa, comunica lembranças e brinca com a memória, mostrando, ao final, além da versão do autor da lembrança, uma "versão popular" de sua própria história, em forma de cordel:

\author{
O meu nome é Viajante da Silva \\ Eu tenho fama de brabão \\ qualquer parada eu topo \\ e comigo não tem sabão \\ porque foi o patrão que mandou \\ eu resolver esta questão \\ eu fui criado no sul \\ conheço toda a tramóia \\ nasci lá em Niterói \\ na terra do Araribóia.
}

Como narradores e contadores de outros tempos, mostramos como bebemos na fonte de nossas próprias experiências ou de aventuras dos outros, transmitidas de boca em boca, para criarmos uma história de vida que é quase nossa e nunca exclusivamente nossa. 


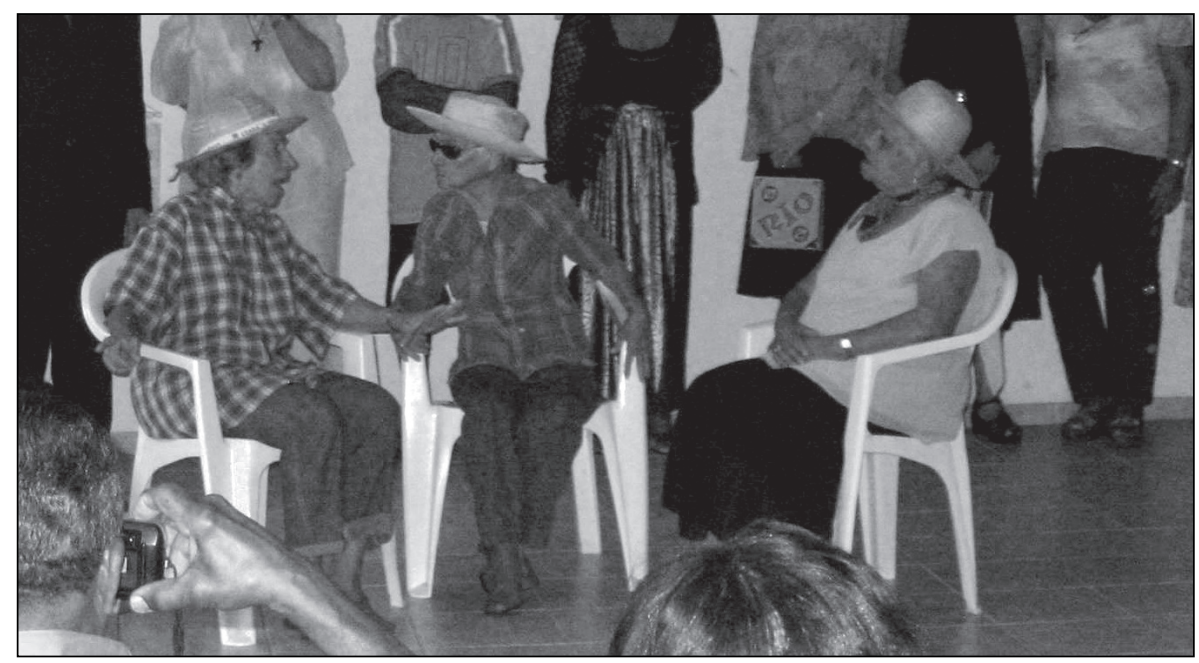

Fotografia 5: Narradores.

\section{Considerações Finais}

A tradução do arquivo de lembranças em formas breves de dramaturgia revelou alguns caminhos tomados pelo processo de rememoração do passado e as transformações ocorridas nos diferentes registros deste processo. Os relatos orais das recordações já nascem como reconstrução de um passado, pois a distância temporal, a contaminação do olhar do tempo presente, a necessidade humana de situar e justificar o que foi vivido imprimem, imediatamente, no discurso um viés ficcional. Num segundo momento, quando são transformadas em roteiros ou textos, ganham outras qualidades de emoção, seja pela junção de lembranças de vários autores, seja pela premência de organizar o que surgiu na efervescência de desabafos desordenados. Nesse momento, a noção de autoria se perde, as lembranças sem dono são de todos e de ninguém. E, finalmente, levadas ao palco, é possível brincar com elas, trocar as emoções e os humores originais. De individuais, as memórias passam a pertencer ao grupo. São olhadas com um novo distanciamento, sendo possível aprender com elas sobre o ser humano e a diversidade de sentimentos que nele habita. Representá-las em cena exige que o grupo recorra às suas concepções do fazer teatral, reportando-se para o teatro que conheceram e que ainda admiram. As escolhas estéticas acenam, então, para alguns clichês melodramáticos atenuados pelos recursos da comédia. Incorporados à representação social de teatro aí revelada, estão os novos códigos teatrais apreendidos nas oficinas, fazendo surgir um 
modo próprio destes atores de fazer e pensar o teatro para contar as suas memórias no palco.

As apresentações nem sempre acontecem em espaços convencionais. Quando temos a oportunidade de estar em um teatro, é possível a utilização de recursos de iluminação e de um arranjo melhor no cenário. No entanto, vários são os convites para nos apresentarmos em salões, auditórios, lonas, shoppings e ambientes improvisados. No palco, no tablado ou simplesmente na frente ou no meio de uma platéia atenta e participante, utilizamos mesas e cadeiras, objetos fáceis de serem encontrados em qualquer lugar. O que interessa, particularmente, é a possibilidade de partilhar o longo trabalho de criação dos espetáculos. E em cada uma destas montagens habita um minucioso trabalho de relembrar e criar, de pensar sobre si mesmo e representar, sem provocar um afastamento entre os dois atos. E neste gesto generoso de oferecer suas lembranças em forma de arte, uma relação de cumplicidade se estabelece entre o grupo e a platéia que nos assiste.

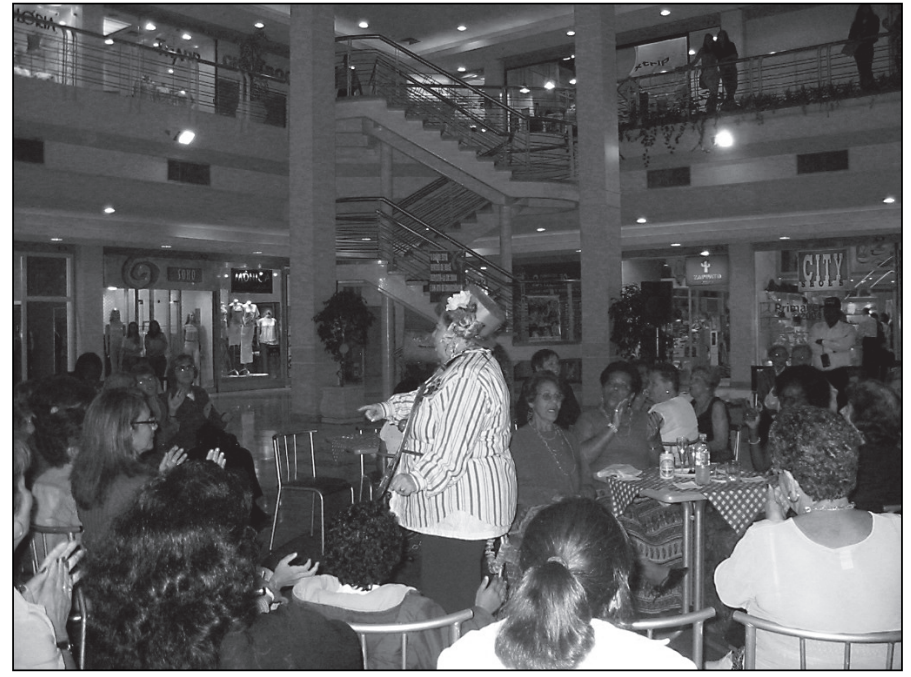

Fotografia 6: Espetáculo “Um Boteco e suas Histórias” apresentado na praça de alimentação de um shopping center.

A recepção dos espetáculos revela, em alguns momentos, uma relação catártica com o público, fazendo-o identificar-se e emocionar-se com o que assiste. Por outro lado, faz renascer, junto com a platéia, a memória atualizada de vivências de uma geração. Além disso, cria, talvez de um modo enviesado, um tipo de intermezzo no que alguns sociólogos denominam de “memória comum" (NAMER, 2000). 
Esta "memória comum", formada a partir de um bombardeamento de informações veiculadas pelos meios de comunicação de massa, é caracterizada pela passividade generalizada dos indivíduos que a recebem, sem tempo suficiente para digeri-la, sem a oportunidade de associar o vivido e a memória representada, como se estivessem diante de um contínuo atualizador de imagens. O massacre de informações novas, ininterruptamente, provoca uma "memória saturada", conforme assinalou Régine Robin (2003). Saturação por uma colocação entre parênteses de um passado próximo, mas não pensado, não criticado, não decantado. Uma indiferenciação dos acontecimentos, uma ausência de triagem, uma banalização da memória e, ao mesmo tempo, uma necessidade de estocar, arquivar (ROBIN, 2003). Todos os acontecimentos mundiais são transmitidos, simultaneamente, pela televisão, pela Internet ou por outros meios de comunicação. Com a espetacularização dos fatos, a mídia faz com que o público seja atingido em suas emoções, sem tempo hábil para articular a significação afetiva e intelectual.

Contando histórias de suas histórias, nosso grupo tem convidado a platéia que nos assiste a se emocionar e, ao mesmo tempo, a pensar sobre suas vidas inscritas por costumes e hábitos de uma época determinada.

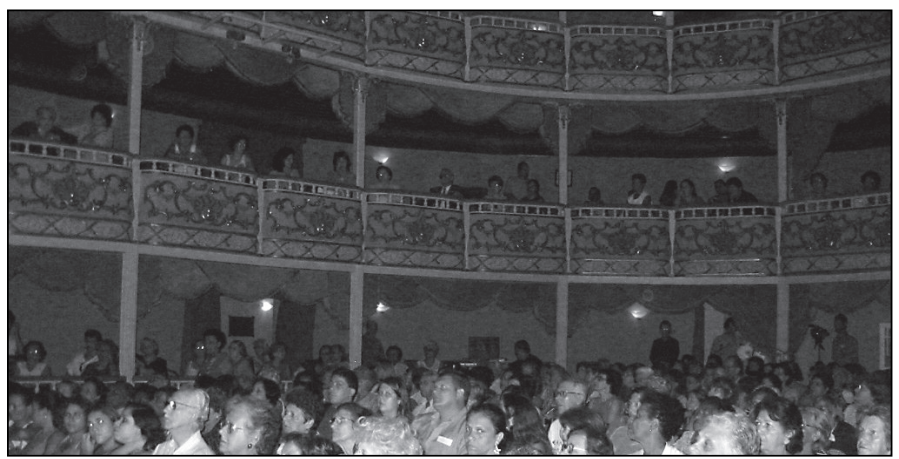

Fotografia 7: Platéia do Teatro Municipal de Niterói.

Durante estes anos de investigação, para lá dos estilos ou gêneros, procuro descobrir os motores do jogo em cada território que inspiram o processo de criação destes velhos sujeitos. Isto porque as formas dramáticas que procuro estão "[ . . . ] seguramente mais próximas deste teatro inscrito na vida quotidiana e cujos atores nem sempre têm uma formação técnica tradicional." (RYNGAERT, 1981, p. 66). Poderia dizer que o registro cênico-dramatúrgico aqui apresentado é fruto de um trabalho artesanal e em processo, cujas formas estão sempre por vir. 


\title{
BRIEF MEMORY DRAMA: elderly workshop
}

\begin{abstract}
This article aims to analyse the process of an elderly theater group. The theater and its particular language are a good way to express the memories and understand the elders' subjectivities. As a result, a new way of communication experiences and memories is created. Keywords: Elderness. Memory. Theatre.
\end{abstract}

\section{REFERÊNCIAS}

BOAL, Augusto. O Arco-Íris do Desejo: método Boal de teatro e terapia. Rio de Janeiro: Civilização Brasileira, 1996.

NAMER, Gérard. Halbwachs et la Mémoire Sociale. Paris: L'Harmattan, 2000.

ROBIN, Régine. La Mémoire Saturée. Paris: Stock, 2003.

RYNGAERT, Jean-Pierre. O Jogo Dramático no Meio Escolar. Coimbra: Centelha, 1981.

VANOYE, Francis; MOUCHON, Jean; SARRAZAC, Jean-Pierre. Pratiques de L'Oreal. Paris: Armand Colin, 1991.

VENANCIO, Beatriz Pinto. Teatro de Lembranças: registro cênico-dramatúrgico da memória. 2004. 198 f. Tese (Doutorado em Teatro) - Universidade Federal do Estado do Rio de Janeiro, Rio de Janeiro, 2004.

Recebido em: 18-01-2008

$1^{a}$ revisão: 03-04-2008

$2^{a}$ revisão: $23-11-2008$

Aceite final: $28-11-2008$ 